\title{
13
}

\section{Monitoring and Reporting Land Use Change and Its Effects on the Queensland Environment}

\author{
Paul Lawrence, Craig Shephard, Phillip Norman, \\ Christina Jones and Christian Witte
}

\section{Key Points}

- Land use datasets and their application to inform and influence decision-making require a combination of technology, scientific credibility, interpretative artistry and cross-disciplinary collaborations.

- The Queensland Land Use Mapping Program (QLUMP) has been instrumental in providing land use information to assist decisionmaking and investments by government to reduce the pollutant loads from catchments adjacent to the Great Barrier Reef.

- Products generated through QLUMP, such as the type of land use and monitoring changes in land use patterns across Queensland, provide lines of evidence to support priority programs, such as the Reef Water Quality Protection Plan, the South East Queensland Regional Plan, strategic cropping land and the State of the Environment.

- These applications demonstrate the value of adhering to the Australian Collaborative Land Use and Management Program (ACLUMP) guidelines to ensure a methodology is consistent, accurate, reliable, cost-effective and makes best use of available ancillary databases and data management infrastructure. 
- Several emerging land use policy and planning issues in Queensland, and benefits from scientific and collaborative arrangements for land use mapping to inform and influence state and national scale issues are explored.

\section{Introduction}

Land use information is critical for planning, policies and decisionmaking. The availability of consistent and reliable information is essential for sustainable natural resource management (NRM) and environmental outcomes for local, state and federal governments, regional NRM groups, industry groups, community groups and land managers. The value of land use information is particularly evident when it is available at temporal and spatial scales that are fit for purpose, and when it is analysed in combination with other spatial datasets that inform decision-making, such as modelling, monitoring and economic evaluations.

The Queensland Spatial Information Council defined land use as a foundation spatial dataset that is 'vital for the progression and development of Queensland' (Queensland Government, 2017). The use of and reliance on land use mapping for priority programs and government initiatives have increased in recent years. The purpose of this chapter is to review some of the applications in Queensland that have benefited from the incorporation of land use information, both as a primary source and in secondary and supportive roles. Case studies, including the Reef Water Quality Protection Plan, the South East Queensland Regional Plan and Cape York Regional Plan, serve to highlight the use of land use information to assist decision-making and investments by government. This chapter shows the value of a nationally recognised standard in land use classification. This is particularly evident for cross-jurisdictional programs, such as the Murray-Darling Basin and agricultural development in northern Australia. Observations on the future directions and technological challenges for land use mapping for dynamic reporting-particularly the extent to which these might facilitate the continuing enhancement of land use planning products, readying them to inform complex non-routine and multi-stakeholder NRM issues - are offered by way of conclusion. 


\section{Land Use Mapping in Queensland}

The Queensland Land Use Mapping Program (QLUMP) is the primary vehicle for deriving spatial and change detection information on land use within the state. The program is a partnership between the Remote Sensing Centre, Department of Science, Information Technology and Innovation (DSITI) and Regional Service Delivery, Department of Natural Resources and Mines. The input of regional staff throughout Queensland is crucial; their mapping skills, local knowledge and capacity to engage regional experts in compiling updated land use mapping contribute to the overall accuracy of the program.

Since commencing in 1998, QLUMP has been active within the Australian Collaborative Land Use and Management Program (ACLUMP), which includes all jurisdictions and is coordinated by the Australian Government's Department of Agriculture and Water Resources (Australian Bureau of Agricultural and Resource Economics and Sciences, 2011). Mapping is undertaken to a national standard, and Queensland scientists have influenced the national mapping methodology; this reflects the adaptive and applied nature of the land use mapping framework, as well as the success of the collaborative partnership.

The technical foundation of QLUMP has evolved over time; it utilises the latest techniques for identification, compilation and management of spatial data. Originally, the land use maps were compiled in a raster environment, using Landsat TM (Thematic Mapper) and ETM+ (Enhanced Thematic Mapper Plus) satellite imagery. Improvements in vector data enabled QLUMP to transition to editing in a vector environment (e.g. the Earth Sciences and Resources Institute's ArcGIS, a geographic information system [GIS] for working with maps). More recent applications, including the 2009 maps showing land use in the Great Barrier Reef catchments, have benefited from innovative workflow systems to manage and coordinate land use mapping by individual spatial officers across the state. For example, the Earth Sciences and Resources Institute's ArcSDE (Spatial Database Engine) geodatabase replication infrastructure efficiently allocated each spatial officer a specific region requiring update; provided spatial officers with the most up-to-date version of the data; enabled spatial officers to map their region on their own computer before submitting edits to the original database; and authorised QLUMP managers to perform quality assurance, before committing data to the 
original database. Through this process, over 800,000 individual edits were performed by QLUMP across nine regional offices in Queensland, with each edit checked within a quality-assured framework. Without the efficient management and exchange of spatial data, the update of land use in the Reef catchments-which cover 380,000 square kilometres-to a consistent format, could not have been achieved within the time frame.

Further developments in QLUMP methods have been driven, in part, by improved ancillary data; in particular, the increasing availability of suitable datasets that aid land use interpretation. These have been incorporated into workflow processing through a GIS dichotomous decision-tree approach (Lawrence \& Shephard, 2014). Ancillary data layers are queried in accordance with the Australian Land Use and Management Classification (ALUMC) hierarchy (in combination with the decision rules) to output a 'flattened' spatial layer representing land use; in certain circumstances, known features (e.g. estates) can be 'cut' straight into the mapping layer to aid efficiency and accuracy.

QLUMP now utilises a tablet personal computer to undertake fieldbased editing, run ArcGIS and access all the ancillary and imagery data normally available at the desktop. This allows officers to efficiently edit and annotate land use maps in the field, thereby reducing the duplication of work.

Advances in the acquisition, access, availability, resolution, cost and timeliness of suitable imagery have greatly influenced the quality of land use data. Whereas image data were once scarce and coarse (e.g. Landsat 30 metres), QLUMP now uses high-resolution state-wide imagery (e.g. SPOT 6/7 1.5 metres) to update land use, and higher-resolution orthophotography (10 centimetres) is available for some coastal catchments. In addition, there are numerous freely available image sources, such as Google Earth and Street View imagery, that have proved to be great resources for updating land use in intensive regions (e.g. southeast Queensland).

While higher spatial resolution imagery is becoming more accessible, the challenge for land use mapping remains the temporal resolution. This presents limitations for mapping and decision-making, particularly for seasonal or opportunistic land uses (e.g. summer-winter cropping) and temporary or episodic events (e.g. flood mapping, channel erosion and fire). Typically, the acquisition of highly temporal and coarse data 
(e.g. Landsat 30 metres) is prompt and free, while the acquisition of high-resolution data (e.g. orthophotography) is delayed and expensive. Improving the supply chain and delivery of high-resolution imagery would result in significant improvements for providing timely land use information. The spatial resolution of imagery is also important with respect to the intensity of land use. The greatest efficiencies are found in applying a mix of both high-temporal (yet course) resolution imagery and high-spatial (yet untimely) resolution imagery to compile the most recent land use maps.

A recent example of this approach is the updated land use map for the Tully catchment in north Queensland. In response to the recent Panama Disease Tropical Race 4 biosecurity issue, QLUMP acquired the most recent SPOT 6/7 satellite imagery for the agricultural production areas within the Tully catchment, supplemented by coarser imagery elsewhere. This enabled QLUMP to compile a five-week-old high-resolution land use map for Biosecurity Queensland. Information management and knowledge exchange remain core pillars of the QLUMP system. The QLUMP DocuWiki environment (i.e. in-house documentation) ensures a consistent approach to the management of work procedures, nomenclature in file naming, data sources, decision rules, terminology and access to knowledge.

\section{Some QLUMP Applications}

Land use mapping (see Figure 13.1) allows governments, stakeholders and land managers to:

- describe the type and extent of land uses, and explain how land use decisions align with policy goals and their environmental, economic and social challenges

- support analysis of the extent and effects of land uses on agriculture, natural resources, the environment and regional communities

- consider the influences of land use change decisions relative to on-site and off-site impacts, and assess changes in land use that result from regulation, policy and incentives. 


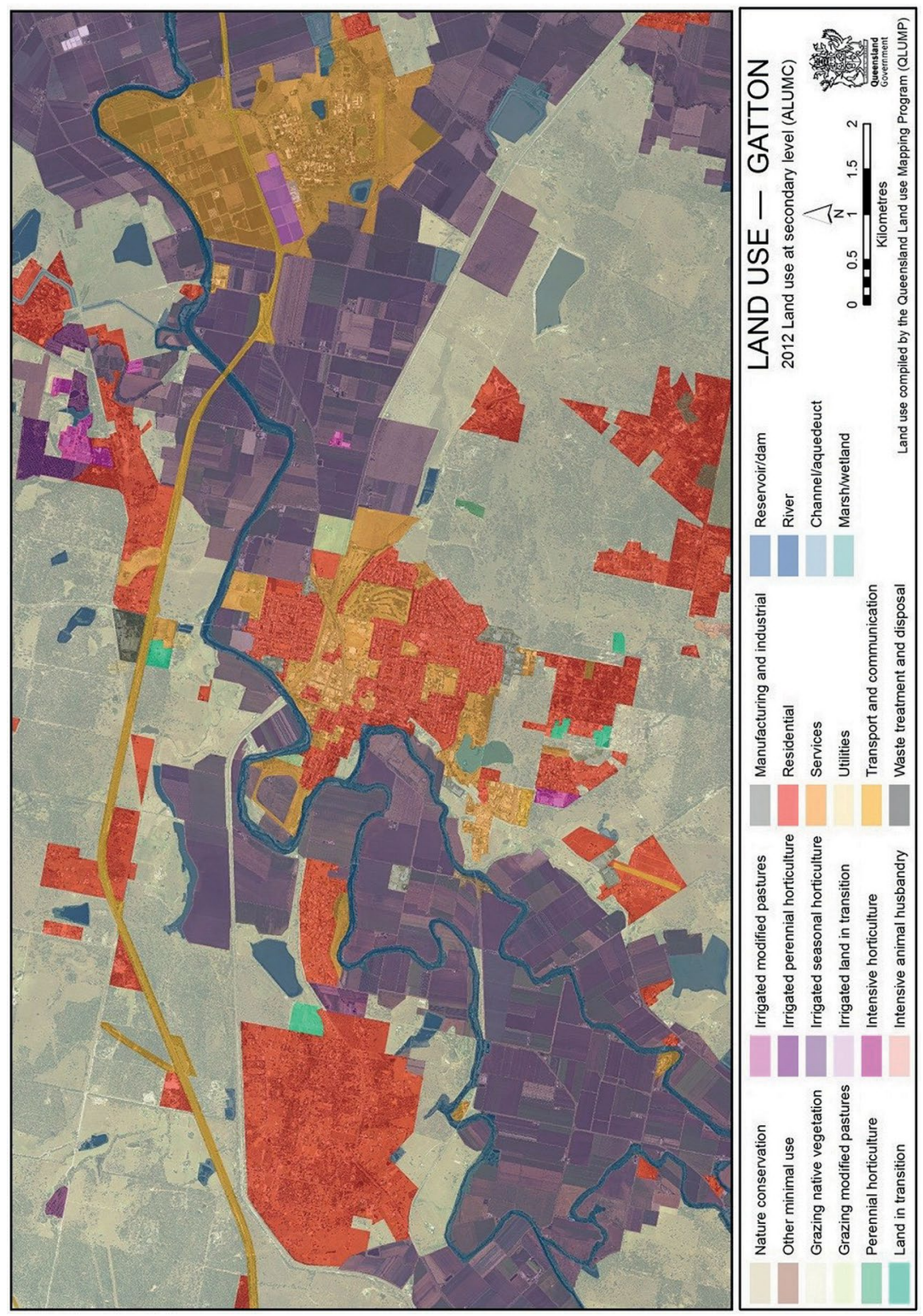

Figure 13.1: Land use mapping example-Gatton, South East Queensland.

Source: Queensland Government (2017). 
The demand for timely land use information is broad; it is applied across a range of NRM issues, with particular focus on the rural sector. During 2013, there were approximately 1,700 downloads of QLUMP datasets from the Queensland Spatial Catalogue-QSpatial. The portfolio of applications and supplementary mapping covers a spectrum of information and products, including:

- agricultural productivity and sustainability (i.e. profitable production of food and fibre and adoption of sustainable agricultural practices)

- land use planning (i.e. supporting regional planning and investment, and strategies for development)

- biosecurity (i.e. managing invasive species and minimising the impact of incursions, managing weeds and feral animals and their impact on threatened species and evaluating the risk of disease spread in crops)

- natural resource condition monitoring and investment (i.e. setting soundly based targets and monitoring procedures for natural resource investment at national, state, regional and local levels of responsibility)

- biodiversity conservation (i.e. managing and mitigating the effect of production systems on terrestrial, aquatic, coastal and marine habitats)

- improving water availability and quality (i.e. responding to water allocation and efficiency needs; responding to water deficits arising from drought and the need for increased environmental flows; and managing water quality, including sediment and nutrient loads)

- natural disaster management (i.e. preparing for, responding to and evaluating the impact of events such as floods, cyclones, bushfires and drought).

In updating catchment-scale land use mapping, QLUMP also revises older mapping to account for improvements or corrections. Defensible land use change data that show actual land use change, rather than improvements to the mapping, are then derived at the secondary level of the ALUMC to reflect the consistency of mapping across the catchment. For example, land use change from rural residential to urban will not appear in the land use change dataset; this is because it is at the tertiary level of the classification.

QLUMP produces land use summary reports for each catchment, including maps, summary statistics, data limitations and results of the accuracy assessment. Land use change is presented relative to the change in intensity of the land use at the secondary level of the ALUMC. 
A change from 2.1.0 (grazing native vegetation) to 2.2.0 (production forestry) represents an increase in land use intensity, while a change from 2.1.0 (grazing native vegetation) to 1.1.0 (nature conservation) represents a decrease. Further analysis of the change, both from and to specific land use classes, is also undertaken. As a result, change can be expressed in terms of extent (in hectares or percentages) or intensification-deintensification. An experimental weighted change model is being considered to reflect the range of intensity of land use changes and account for the 'absorbing state'. For example, a land use change from one estate (e.g. managed resource protection) to another (e.g. nature conservation) is not as significant as a land use change to an intensive land use class (e.g. mining or residential). However, further value-adding with catchment modelling or land use pattern modelling remains largely untested.

Another priority application for QLUMP information is the parameterisation of catchment-scale modelling for the Reef Plan. The alignment of land use with management practice data is essential for accuracy in delivering credible responses towards achieving water quality and management targets on an annual basis. Changes in land use within the reef catchments are now routinely incorporated into the recalibrated catchment modelling. Similarly, the crop frequency model, which informs Queensland's Strategic Cropping Land Act 2011, relies on QLUMP data to reduce and mitigate commission errors.

\section{Critical Issues and Future Opportunities}

The full potential of land use mapping to inform decision-making is constrained by several critical issues.

\section{Currency}

While information for parts of Queensland has been updated, the 1999 (state-wide) baseline is still the only data available for 50 per cent of Queensland (see Figure 13.2). QLUMP has progressively updated catchment-scale land uses on an ad hoc basis, generally in response to policy demands and acquisition of suitable imagery. For instance, the Great Barrier Reef catchments data were updated in 2009 to support the Reef Plan. Ideally, QLUMP strives to maintain the currency of land use in Queensland as per ACLUMP guidelines (i.e. nominally five years in coastal catchments and 10 years elsewhere). 


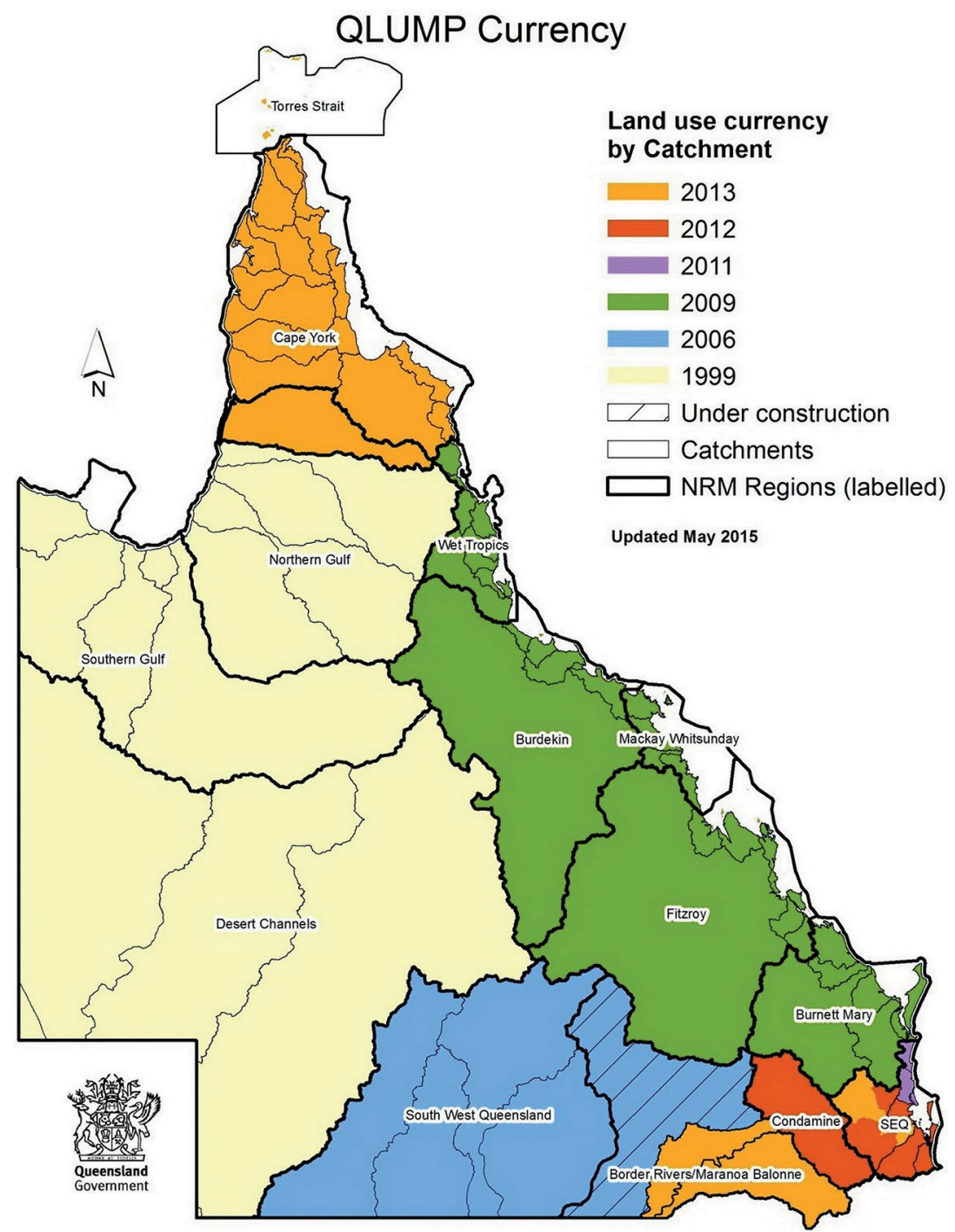

Figure 13.2: Land use currency mapping for Queensland.

Source: Queensland Government (2017).

\section{Imagery}

QLUMP relies on the government's Spatial Imagery Acquisition Program (SIAP) to acquire suitable imagery. Negotiated licence agreements provide access to contributing agencies. While the main focus of the program is aerial photography captured for urban and intensive land use areas, 
high-resolution state-wide satellite imagery purchases have also been supported-specifically, 2009 and 2012 SPOT 5 imagery, and 2013 SPOT 6 imagery. Suitable imagery for western regions and catchments (e.g. Landsat) is available without cost through the United States Geological Service - NASA website, while SPOT 5 (or similar) satellite imagery and high-resolution orthophotography are purchased for specific regional priorities (e.g. Murray-Darling Basin and reef catchments) (DSITI, 2015). The QLUMP program works closely with SIAP to drive potential efficiencies, as QLUMP is well positioned to update and add value to the land use component (from all suitable imagery) for other spatial mapping products. Targeting potential regional growth areas through a compilation of spatial information (including land use type and change) should also be considered to improve the full return on investment.

\section{Data Substitution}

QLUMP has participated in ACLUMP pilots that seek to improve the currency of existing land use data through alternative sourcing. One such pilot, Updating Land Use by Exception, used land valuation data from the Queensland Valuation System (QVAS) to compile land use and land use change (Ground, Lawrence \& Shephard, 2013). The success of this approach revealed several limitations in terms of spatial and temporal accuracies; for example, it returned a low correlation (Kappa) score. Figure 13.3 shows an example of the differences in land use mapping for a section within the Goondiwindi region of the St George area, highlighting the differences in type and extent of land use change between 1999 and 2006. These differences may be attributed to the nature of QVAS data, which are not updated to the same frequency or consistency. Additionally, QVAS is geometrically derived from the Digital Cadastral Database (DCDB) and cannot represent land use at the sub-parcel level. While some jurisdictions have opted to use valuation property classification coding, this approach is not recommended for Queensland, where spatial and thematic accuracy at the sub-parcel level provides the best support for science, policy and planning applications. 


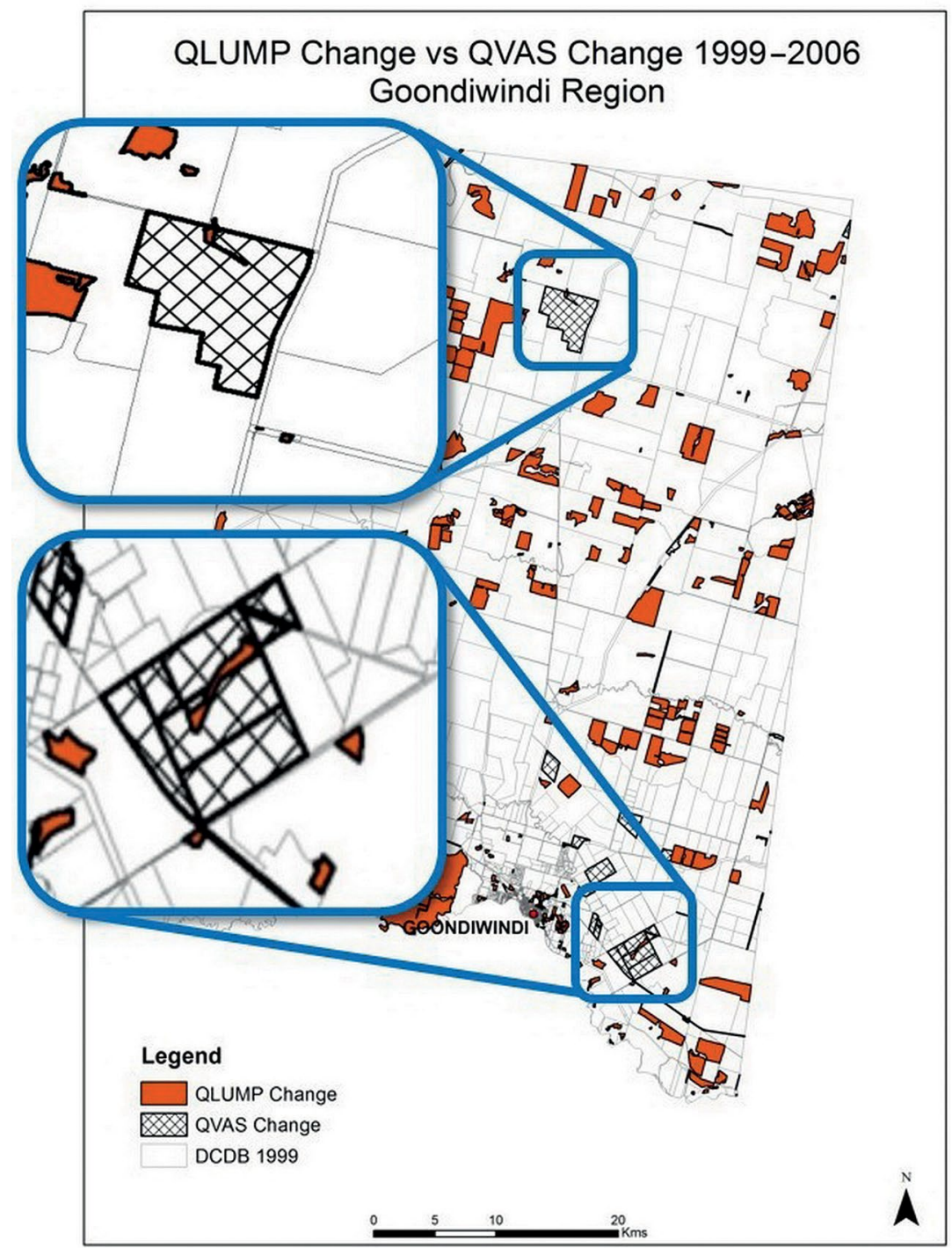

Figure 13.3: Comparison of land use mapping classification at sub-parcel level-Goondiwindi region, south-west Queensland.

Source: Queensland Government (2017).

\section{Impact Mapping}

The spatial change in land use may not be proportional to the impacts on water quality and ecosystem services. Although extent and resolution are fundamental, impacts from relatively small footprint industries, 
such as coal seam gas installations, vegetation within ephemeral macrochannels or land management practices, may not be detected from coarser resolution imagery, yet these may contribute to catchment processes and environmental management. Consequently, a challenge for remotesensing sciences is to utilise spatial imagery across a range of spatial and temporal scales to detect micro-scale, high-impact changes.

\section{Recommendations}

Land use datasets are key economic enablers for the development of the state's natural resources; at the same time, they maintain a high degree of environmental protection by objective measurement. The data are used widely across the Queensland Government, and externally by regional NRM bodies, industry bodies, consultants, local governments, research agencies and community groups. The national coordination provided by ACLUMP has been critical to the success of land use mapping in Queensland. The consistent and defensible mapping generates information, knowledge and communication products to inform policy and planning decisions with confidence, now and into the future.

Basic land use types are now routinely monitored and mapped in Queensland; however, access to new imagery to provide increased temporal and spatial resolution of land use is required to mature these early gains in land use identification. New concepts that involve heuristic, multiple-criteria analysis and dichotomous 'intelligent' identification of land use management must be researched and validated to respond to more complex and 'wicked' problems involving soil and water quality outcomes. Equally, changes in land use should be expressed in units that convey impact as well as extent of the mapping area.

\section{References}

Australian Bureau of Agricultural and Resource Economics and Sciences. (2011). Guidelines for land use mapping in Australia: Principles, procedures and definitions (4th ed.). Canberra, ACT: Australian Bureau of Agricultural and Resource Economics and Sciences. 
DSITI (Department of Science, Information Technology and Innovation). (2015). Land use summary 1999-2013: Border Rivers and Moonie catchments. Brisbane, QLD: Department of Science, Information Technology and Innovation.

Ground, S., Lawrence, L. \& Shephard, C. (2013, April). Monitoring land use: Land use change and land management practices within the Queensland Murray-Darling Basin: A comparison of Queensland land use mapping programs and Queensland valuation systems. ACLUMP Technical Workshop, Canberra, ACT.

Lawrence, L. \& Shephard, C. (2014, April). Updating land use mapping by exception-a GIS decision tree approach. ACLUMP Technical Workshop, Bendigo, VIC.

Queensland Government. (2017). Queensland land use mapping program (QLUMP). Retrieved from www.qld.gov.au/environment/ land/vegetation/mapping/qlump-background 
This text is taken from Land Use in Australia: Past, Present and Future, edited by Richard Thackway, published 2018 by ANU eView, The Australian National University, Canberra, Australia.

doi.org/10.22459/LUA.02.2018.13 